\title{
IMPACT OF INFARCT RELATED ARTERY AND ITS PATENCY ON THE OUTCOMES OF PATIENTS UNDERGOING PRIMARY PERCUTANEOUS CORONARY INTERVENTION

\author{
Mohammad Ibrahim Alameddin ${ }^{1}$, Mesbah Taha Hasanin ${ }^{2}$, Tamer Mohamed Mostafa ${ }^{3}$, Wael Ali \\ Khalil $^{4}$
} \\ Cardiology departments, National Heart Institute, Giza ${ }^{1}$, Zagazig university ${ }^{2,3,4}$,Egypt
}

\author{
Corresponding author \\ Mohammad Ibrahim \\ Alameddin. \\ $\underline{\text { m3alamdien@gmail.com }}$
}

\begin{abstract}
Background: Primary percutaneous coronary intervention (PCI) for acute myocardial infarction might be associated with suboptimal coronary flow with consequent poor functional recovery and higher rate of complications. Identification of the predictors of reperfusion failure can increase the rate of procedural success, preserve ventricular function and lessen mortality. We aimed to find the association between baseline coronary patency \& culprit site with PCI outcome and the incidence of major adverse cardiac events (MACE).

Methods: 46 STEMI patients treated by primary angioplasty were enrolled, then grouped according to the infarction related artery patency graded by TIMI flow. Over the next 3 months, patients were followed for the incidence of stent thrombosis, re-infarction, acute decompensated HF \& death.

Results: 27 patients had initial TIMI 0 flow and 19 patients had initial TIMI $\geq 1$ flow. The proportion of satisfactory PCI outcome was $44.4 \%$ and $78.9 \%$ respectively $(\mathrm{p}=0.019)$. The later incidence of MACE was $66.7 \%$ and $21.1 \%$ respectively $(\mathrm{p}=0.002)$. The culprit vessel was LAD, LCX and RCA in $54.3 \%$, $10.9 \%$ and $34.8 \%$ of the cases. When grouped based on the culprit, incidence of MACE was $68 \%, 20 \%$ and $25 \%(\mathrm{p}=0.011)$. Multivariate logistic regression analysis found that initial TIMI 0 flow $(\mathrm{p}=0.013)$ and LAD as the infarction related vessel $(\mathrm{p}=0.032)$ were independent predictors for MACE.

Conclusion: Initial infarction related artery patency at angiography has a direct impact on PCI outcome. Baseline TIMI 0 flow and LAD as a culprit site are independent predictors for major adverse cardiac events in STEMI patients undergoing primary angioplasty.
\end{abstract}

Key words: STEMI, primary PCI, TIMI flow, LAD, MACE.

\section{INTRODUCTION}

$\mathrm{F}_{\mathrm{s}}$ ollowing the acute ischemia caused by occlusion of a coronary artery in the setting of STEMI, myocardial necrosis ensues within few hours. ${ }^{[1]}$ Rapid reestablishment of coronary flow can enhance ventricular function and lessen mortality. ${ }^{[2]}$ Primary percutaneous coronary intervention (PCI) is the proved method of reperfusion all around the world. ${ }^{[3]}$ It has enhanced the survival in STEMI patients compared with thrombolytic therapy by restoring greater proportions of antegrade coronary flow and evading intracranial hemorrhage. ${ }^{[4]}$

Despite the progress in the angioplasty \& stenting procedures, initial PCI was still associated with a percentage of suboptimal coronary TIMI flow. ${ }^{[\mathbf{5 , 6}}$ Some patients still have an impairment of myocardial reperfusion despite opening of the culprit vessel with a subsequent negative effect on the clinical outcome reversing the potential benefits of primary PCI, ${ }^{[7,8]}$ in addition to delayed recovery of ventricular function after an acute myocardial infarction. ${ }^{[9]}$ Factors that affect the recovery of ventricular function are the size of the infarction, the flow in the infarction related artery, asynergy and elevated wall stress. ${ }^{[10]}$ Prevention, anticipation, immediate detection and treatment of no reflow may alter the outcome of PCI.

We aimed to find the association of initial infarction related artery patency upon diagnostic angiography with the immediate PCI outcome and the incidence of later major adverse cardiac events.

\section{Study population}

\section{MATHODS}

We performed a single-centre, observational prospective study of 46 acute STEMI patients whom were planned for mechanical reperfusion by primary angioplasty. 


\section{Mohammad et al..}

Patients were included; regardless of having a previous MI or not; when they presented in the time frame within 12 hours from symptom-onset. The institutional ethics committee accepted the study protocol. All patients provided a written informed consent. Patients who had already received a thrombolytic drug, presented late after 12 hours of symptom-onset, developed cardiogenic shock or required vasopressors or IABP prior to intervention were excluded.

Data collection \& follow-up

Patients were exposed to full history taking, complete general and local examination, 12 lead surface ECG. After receiving loading dose of Aspirin and Clopidogrel, coronary angiogram was performed. Angiographic data were obtained to enable identification of the culprit lesion. Infarction related artery patency was classified in relation to TIMI flow grade. ${ }^{[11]}$ Upon angioplasty, thrombus aspiration device was used if needed. Whenever possible direct stenting was the main modality. Intracoronary nitroglycerine was injected before and after stenting. Control angiogram was done after stenting to evaluate post PCI TIMI flow and potential complications. When the use of GP $\mathrm{IIb} / \mathrm{III}$ inhibitors was imminent, it was infused down-stream in the Cath Lab. Post PCI result was assessed by two independent operators for the presence of residual thrombi, incidence of slow flow/no reflow and grading final TIMI flow. Patients were followed over a period of three months afterwards through phone calls followed by outpatient clinic visits to detect the incidence major adverse events that included stent thrombosis, re-infarction, acute decompensated heart failure necessitating readmission and mortality.

\section{Statistical analysis}

Collected data through history taking, clinical examination, laboratory investigations and outcomes were analyzed using Microsoft Excel, then introduced into Statistical Package for the Social Sciences (SPSS version 20.0). Based on the type of data; qualitative represented as number and percentage, quantitative continues group represented by mean $\pm \mathrm{SD}$. To test differences for significance and association of qualitative variable, Chi square test $\left(\mathrm{X}^{2}\right)$ was used. Multivariate logistic regression analysis was performed to identify predictors of the incidence of major adverse cardiac events March 2019 Volume 25 Issue 2

\section{Zagazig University Medical Journals}

(MACE). Variables used for analysis included age, coronary risk factors, initial TIMI flow grade and site of the culprit coronary artery. P value was set at $<0.05$ for significant results \& $<0.001$ for high significant result.

\section{RESULTS}

Our study included 46 patients. Mean age of the study population was $53.34 \pm 9.6$ years. Male patients represented $87 \%$. Risk factors distribution was $56.5 \%$ for smoking, $43.5 \%$ for diabetes, $45.7 \%$ for systemic hypertension and $10.9 \%$ of the cases had a previous history of ischemic heart disease (Table 1).

Upon initial angiography, $41.3 \%$ of patients showed single vessel disease. Infarct related artery was LAD in $54.3 \%$ of the cases while it was RCA in $34.8 \%$ and LCX in the remaining $10.9 \%$. According to the initial culprit coronary patency, $58.7 \%$ of patients showed TIMI flow grade 0 , while $41.3 \%$ had varying degree of TIMI $\geq 1$ flow. During the interventional procedure, thrombus aspiration was used in $19.6 \%$ of the cases, and direct stent deployment was done for $43.6 \%$ of the cases. Regarding the procedural outcome, $32.6 \%$ of the cases developed slow flow/ no-reflow and residual intra-coronary thrombus was seen in $23.9 \%$. $28.3 \%$ of the cases received an IV infusion of IIb/IIIa inhibitors (Table 1).

Patients with initial TIMI 0 flow had more incidence of residual coronary thrombi $(p=0.07)$, more frequency of slow flow/no reflow $(p=0.04)$, less post PCI TIMI 3 flow $(p=0.13)$ and more frequently required downstream infusion of GP IIb/IIIa inhibitors $(p=0.11)$. Satisfactory PCI outcome was considered when achieving post PCI TIMI 3 flow without any residual thrombi and avoiding the need for IIb/IIIa infusion, and it was significantly associated with baseline TIMI flow $\geq 1$ grade $(p=0.02)$ (Figure 1, Table 2).

During the follow up period over the following three months post intervention, the incidence of stent thrombosis and re-infarction were reported in $4.3 \%$ of the cases, $21.7 \%$ of the patients developed acute decompensated heart failure that necessitated readmission and $6.5 \%$ of them died. Overall, major adverse cardiac events (MACE) had occurred in $47.8 \%$ of the study population (Table 1). 


\section{Mohammad et al..}

When correlating risk profile and angiographic data with the incidence of MACE (Table 3), we found that two factors showed a significant association with the incidence of adverse events; LAD as a culprit artery in those with anterior wall infarction $(p=0.011)$ (Figure 2), and initial TIMI 0 flow of the infract related artery $(p=0.002)$. (Figure 3).

Multivariate logistic regression analysis was performed to determine the predictors for the incidence of overall MACE
Zagazig University Medical Journals

including stent thrombosis, re-infarction, acute HF and death (Table 4). It was found that patient age $(p=0.31)$, LAD as a culprit $(p=0.011)$ and initial TIMI flow $(p=0.002)$ were dependent predictors for the incidence of MACE. Two variables namely; LAD as the infarction related artery $[\mathrm{OR}=2.593 ; 95 \% \mathrm{CI}$ (1.214; 20.184); $p=0.032]$ and initial TIMI 0 flow $[\mathrm{OR}=8.041 ; 95 \%$ CI $(3.003 ; 21.506)$; $p=0.013]$ were independent predictors for the incidence of major adverse cardiac events.

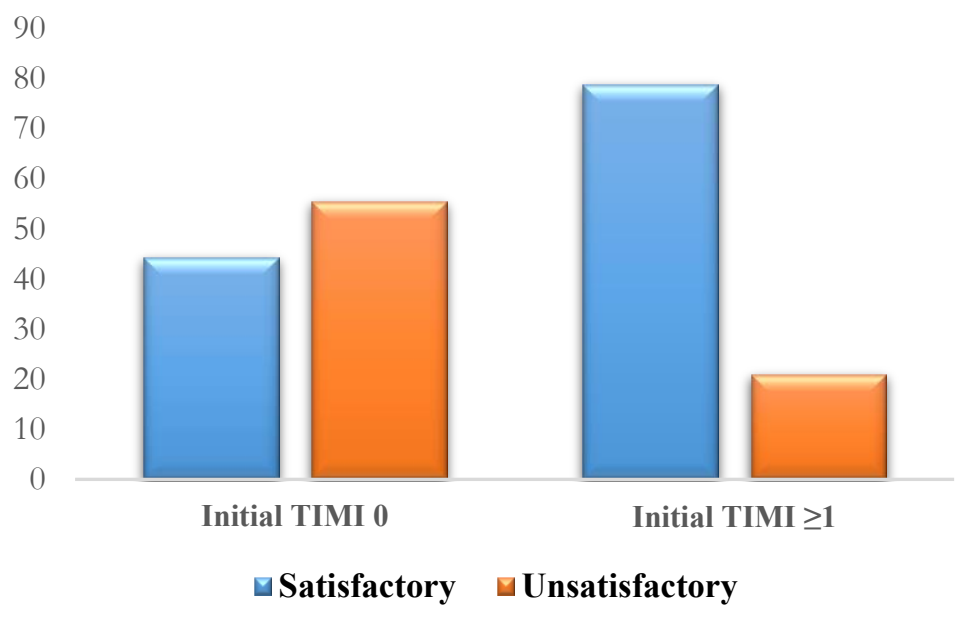

Figure 1. Initial TIMI flow and procedure outcome

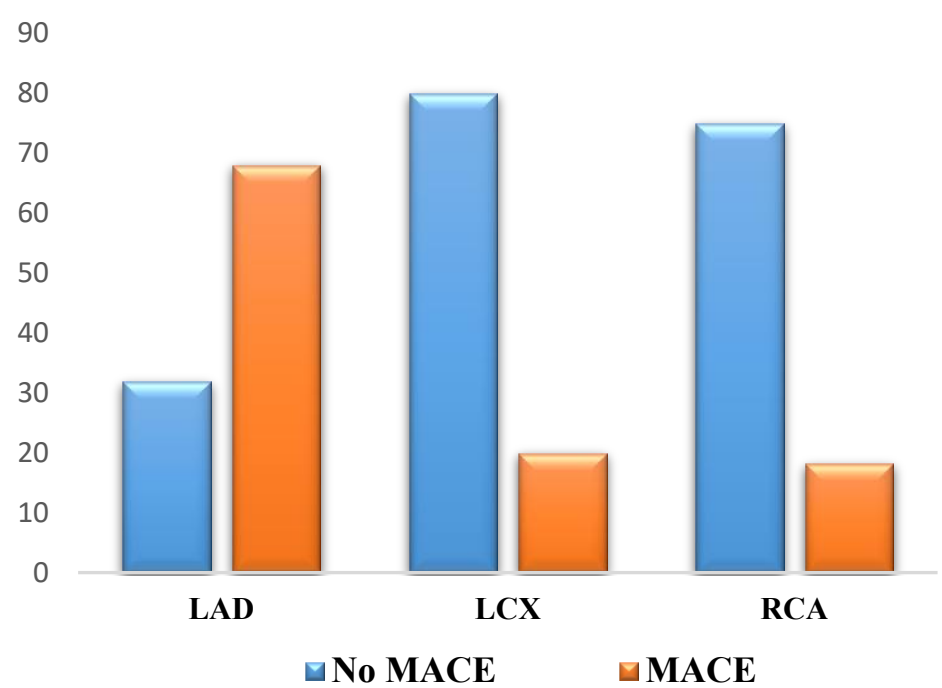

Figure 2. Infarct related artery $\&$ incidence of MACE 


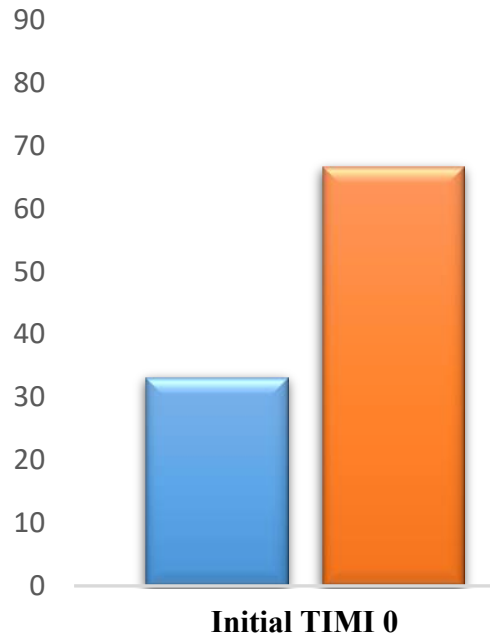

$\square$ No MACE

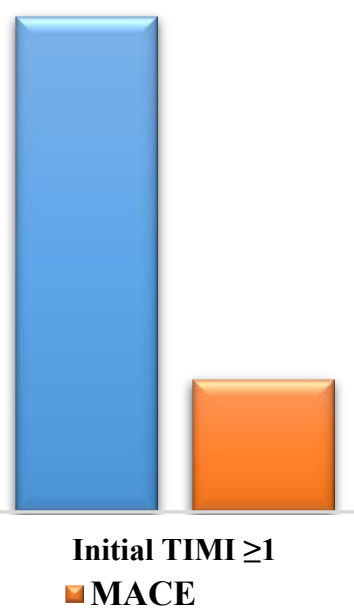

Figure 3. Initial TIMI flow \& incidence of MACE

Table 1. Demographic, risk factors, angiographic \& follow up data

\begin{tabular}{|c|c|c|c|}
\hline \multirow{2}{*}{\multicolumn{4}{|c|}{ Demographic \& risk factors }} \\
\hline & & & \\
\hline \multicolumn{2}{|c|}{ Male } & 40 & $87 \%$ \\
\hline \multicolumn{2}{|c|}{ Female } & 6 & $13 \%$ \\
\hline \multicolumn{2}{|c|}{ Smoking history } & 26 & $56.5 \%$ \\
\hline \multicolumn{2}{|c|}{ Diabetes } & 20 & $43.5 \%$ \\
\hline \multicolumn{2}{|c|}{ Hypertension } & 21 & $45.7 \%$ \\
\hline \multicolumn{2}{|c|}{ Known ischemic heart disease } & 5 & $10.9 \%$ \\
\hline \multicolumn{4}{|c|}{ Angiographic findings } \\
\hline \multirow{3}{*}{ Coronaries affected } & Single vessel & 19 & $41.3 \%$ \\
\hline & Two vessels & 13 & $28.3 \%$ \\
\hline & Multi-vessel & 14 & $30.4 \%$ \\
\hline \multirow{3}{*}{ Infarct related artery } & LAD & 25 & $54.3 \%$ \\
\hline & $\mathbf{L C X}$ & 5 & $10.9 \%$ \\
\hline & RCA & 16 & $34.8 \%$ \\
\hline \multirow{2}{*}{ Initial TIMI flow } & $\mathbf{0}$ & 27 & $58.7 \%$ \\
\hline & $\geq 1$ & 19 & $41.3 \%$ \\
\hline \multicolumn{2}{|c|}{ Use of aspiration thrombectomy } & 9 & $19.6 \%$ \\
\hline \multicolumn{2}{|c|}{ Balloon pre-dilation } & 26 & $56.5 \%$ \\
\hline \multicolumn{2}{|c|}{ Post PCI Slow flow/no reflow } & 15 & $32.6 \%$ \\
\hline \multicolumn{2}{|c|}{ Presence of residual thrombus } & 11 & $23.9 \%$ \\
\hline \multicolumn{2}{|c|}{ Down-stream use of IIb/IIIa } & 13 & $28.3 \%$ \\
\hline \multicolumn{4}{|c|}{ Adverse events on follow up } \\
\hline \multicolumn{2}{|c|}{ Stent thrombosis } & 2 & $4.3 \%$ \\
\hline \multicolumn{2}{|c|}{ Re-infarction } & 2 & $4.3 \%$ \\
\hline \multicolumn{2}{|c|}{ Acute decompensated HF } & 10 & $21.7 \%$ \\
\hline \multicolumn{2}{|c|}{ Death } & 3 & $6.5 \%$ \\
\hline \multicolumn{2}{|c|}{ Overall incidence of MACE } & 22 & $47.8 \%$ \\
\hline
\end{tabular}

MI: myocardial infarction; HF: Heart Failure; MACE: Major Adverse Cardiac Events 
Table 2. Correlating initial coronary patency with the immediate PCI outcome

\begin{tabular}{|c|c|c|c|c|c|}
\hline & \multicolumn{2}{|c|}{ Initial coronary patency } & \multirow{2}{*}{$\chi^{2}$} & \multirow{2}{*}{$p$} \\
\hline & & TIMI 0 & TIMI $\geq 1$ & & \\
\hline \multirow{2}{*}{ Residual thrombi } & $\mathbf{N}$ & 9 & 2 & \multirow{2}{*}{3.18} & \multirow{2}{*}{0.07} \\
\hline & $\%$ & $33.3 \%$ & $10.5 \%$ & & \\
\hline \multirow{2}{*}{ Slow flow/no reflow } & $\mathbf{N}$ & 12 & 3 & \multirow{2}{*}{4.16} & \multirow{2}{*}{0.04} \\
\hline & $\%$ & $44.4 \%$ & $15.8 \%$ & & \\
\hline \multirow{2}{*}{ Final TIMI 3} & $\mathbf{N}$ & 11 & 12 & \multirow{2}{*}{2.24} & \multirow{2}{*}{0.13} \\
\hline & $\%$ & $40.7 \%$ & $63.2 \%$ & & \\
\hline \multirow{2}{*}{ Use of IIb/IIIa infusion } & $\mathbf{N}$ & 10 & 3 & \multirow{2}{*}{2.48} & \multirow{2}{*}{0.11} \\
\hline & $\%$ & $37 \%$ & $15.8 \%$ & & \\
\hline \multirow{2}{*}{ Satisfactory PCI outcome } & $\mathbf{N}$ & 12 & 15 & \multirow{2}{*}{5.47} & \multirow{2}{*}{0.02} \\
\hline & $\%$ & $44.4 \%$ & $78.9 \%$ & & \\
\hline
\end{tabular}

$\chi^{2}=$ chi-squared test

Table 3. Correlation between risk factors and angiographic data with the incidence of major adverse cardiac events (MACE)

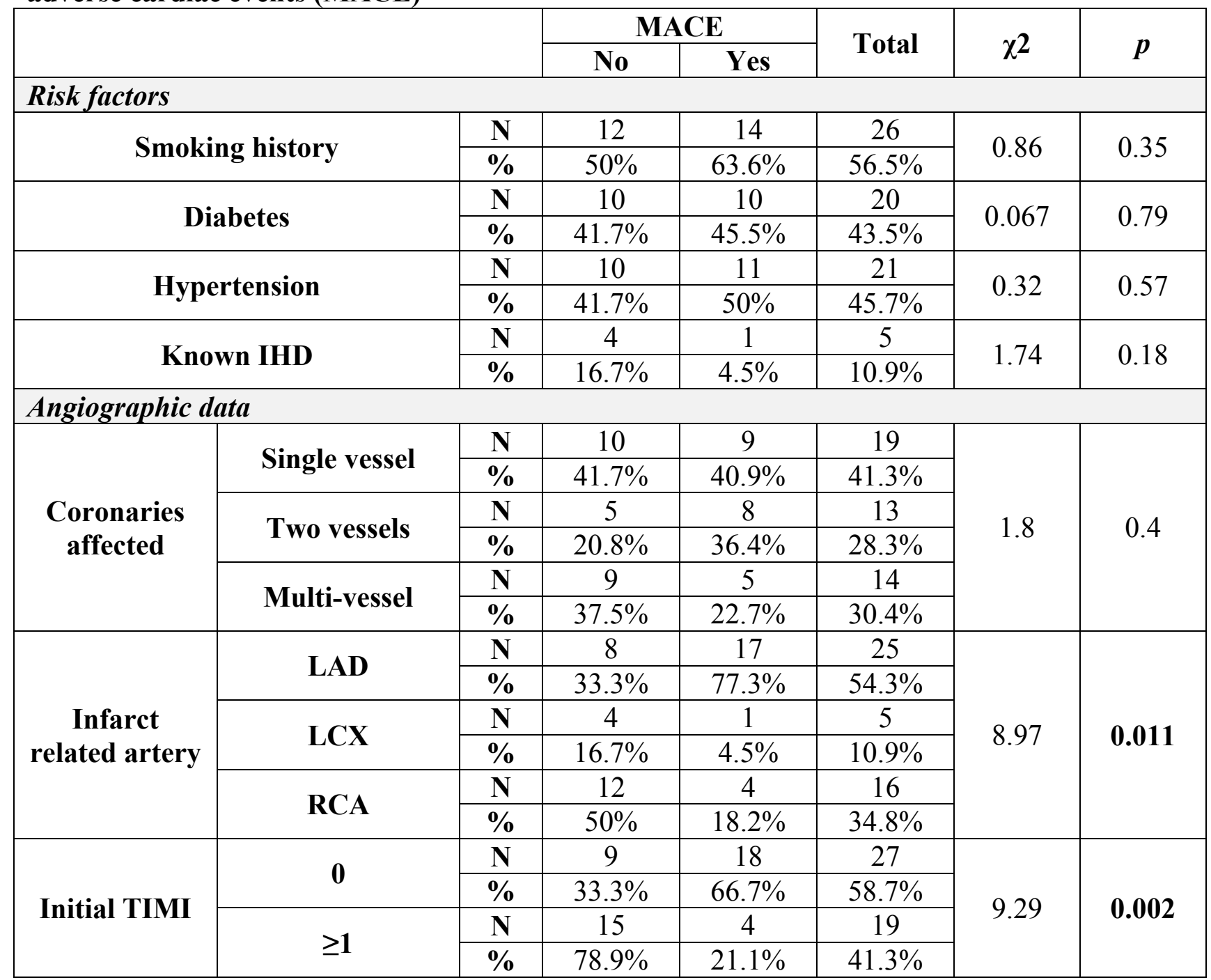

$\chi^{2}=$ chi-squared test

IHD: ischemic heart disease; LAD: Left Anterior Descending, LCX: Left Circumflex; RCA: Right Coronary Artery 


\section{DISCUSSION}

Main findings from our study are: (1) Initial coronary patency before primary PCI with baseline TIMI flow grade $\geq 1$ is significantly associated with immediate satisfactory PCI result by achieving more post PCI TIMI grade 3 flow with less incidence of slow flow/no-reflow or residual thrombi. (2) When the LAD is a culprit in patients with anterior wall infarction, it had a significant association with the incidence of main adverse events. (3) Poor initial coronary patency is significantly associated with the incidence of later MACE including stent thrombosis, re-infarction, readmission with acute decompensated heart failure and death.

The findings of the current study regarding the impact of initial coronary patency on the PCI outcome is in agreement with previous reports, which aimed to find the angiographic features that predict poor post PCI TIMI flow. A sum of 891 patients treated by primary PCI for acute MI were included in two large randomized trials; GUSTO IIb and RAPPORT. It was found that patients with totally occluded culprit coronary artery at presentation tended to have poor final TIMI flow compared with those with non-totally occluded vessels $(p=0.09) .{ }^{[12]}$ Another study enrolled 382 patients with acute MI who underwent primary PCI to identify angiographic findings that predict no-reflow. Univariate analysis showed that TIMI flow grade $\leq 1$ prior to $\mathrm{PCI}$, was linked to no-reflow $(p<0.05)$. Multiple logistic regression analysis identified low baseline TIMI flow on angiography as an independent predictor of no-reflow $(p=0.0002) .{ }^{[13]}$ This was confirmed later on by an analysis of the results of the HORIZONS-AMI trial regarding the total number of 3,845 treated coronary lesions among 3,362 vessels. It was found that baseline TIMI flow $\leq 1$ grade was one of the independent predictors of impaired coronary flow after PCI $(p<0.0001)$. It was concluded that baseline TIMI $\leq 1$ flow was a dominant predictor of suboptimal final TIMI flow. ${ }^{[14]}$ Recently; a randomized trial included 321 patients presenting with STEMI treated by primary PCI. A post-hoc analysis was done to explore the outcome of initial TIMI flow. Final TIMI grade 3 flow was less observed in patients with initial TIMI 0/1 flow ( $p=0.009)$. Stent thrombosis was higher in patients who presented with initial TIMI $0 / 1$ flow $(p=0.048){ }^{[15]}$

Our data about the culprit vessel association with the incidence of adverse events went in line with prior findings of the studies that was designed to assess the impact of the location of the culprit lesion on the outcome. A study included 500 patients who were treated by primary PCI for acute MI to define variations in clinical and angiographic data. Patients in whom the LAD coronary artery was the infarct-related artery showed significantly higher overall mortality during index hospitalization $(p<0.0001) .{ }^{[16]}$ This went in line with a study that reviewed 553 STEMI patients who were treated by primary PCI to clarify the angiographic predictors for reduced LVEF. When LAD was identified as the infarction related artery, patients had lower LVEF $(p<0.01)$ and higher incidence of reduced LVEF $(p<0.01)$. Multivariate analysis established that LAD was the chief determinant of reduced EF after STEMI. ${ }^{[17]}$ Recently; the Polish Registry of Acute Coronary Syndromes analyzed the data of 4581 patients with STEMI who underwent PCI, to evaluate the impact of infarct related artery occlusion on the outcome. Patients were grouped in relation to the culprit artery, and then each group was subdivided according to its initial patency. Totally occluded culprit at baseline angiogram was associated with higher in-hospital $(p=0.0001)$, 6 -month $(p=0.0001)$ and one-year $(p=0.001)$ mortality in comparison with those with patent culprit vessel only when the LAD was the culprit. ${ }^{[18]}$

The findings of our study concerning the impact of initial coronary patency on the later adverse events are in agreement with previous studies that was intended to assess the outcome of poor initial TIMI flow and the impact of pre-procedural flow on mortality. In a study enrolling 1,791 patients with myocardial infarction treated by primary angioplasty., initial TIMI flow was related to enzymatic infarct size $(p<0.001)$, predischarge ejection fraction $(p<0.001)$, and one-year mortality $(p<0.05)$. Multivariate analysis revealed that initial TIMI 3 flow March 2019 Volume 25 Issue 2

www.zumj.journals.ekb.eg 


\section{Mohammad et al..}

grade is an independent predictor of one-year survival $(p<0.05) .{ }^{[19]}$ Discordant data was reached by a prospective registry that included 10,455 patients to evaluate the relationship between baseline epicardial TIMI flow grade and mortality in patients treated with PCI. Of this population, 2,853 were presenting with STEMI. Baseline TIMI flow grade was not an independent associate of either 30-day $(p=0.15)$ or 1 -year mortality $(p=0.20) .{ }^{[20]}$ However, as the HORIZONSAMI trial included 3,602 patients, 3,093 of them underwent primary PCI. Early culprit vessel patency was related to lower mortality at one year $(p=0.04)$, definite or probable stent thrombosis $(p=0.002)$ and total adverse clinical events $(p=0.07)$. In multivariable analysis, early patency of the culprit coronary at baseline angiography was an independent predictor of lesser mortality at one year $(p=0.02) .{ }^{[21]}$ This was confirmed by a study that was conducted on 135 STEMI patients treated by primary angioplasty who presented later on with definite angiographic stent thrombosis. The study aimed to characterize the epicardial coronary flow in patients with angiographic prove of stent thrombosis. 90\% of the cases showed a poor initial TIMI flow $(p<0.01)$. Patients with reduced baseline TIMI flow had less incidence of postprocedure TIMI 3 flow $(p=0.1)$. Patients with baseline TIMI flow $<3$ tended to have greater infarct size $(p=0.07) .^{[22]}$

\section{LIMITATIONS}

Our study included a small set of patient population and follow up period was relatively short. Larger multicenter cohort studies with longer follow up are justified.

\section{CONCLUSION}

Our study established that initial coronary patency upon diagnostic angiography is significantly associated with immediate post PCI TIMI flow. Baseline TIMI flow 0 grade before primary PCI and LAD as the infarction related artery are independent predictors for main adverse cardiac events in STEMI patients treated by primary angioplasty. Our conclusions address the need for development of efficient pharmacological measures to achieve coronary artery patency before PCI.
Zagazig University Medical Journals

Conflict of Interest: Non declared.

Funding: No funding sources.

\section{REFERENCES}

[1] Gersh BJ, Stone GW, White HD, Holmes DR $\boldsymbol{J}$. Pharmacological facilitation of primary percutaneous coronary intervention for acute myocardial infarction: is the slope of the curve the shape of the future? JAMA. 2005; 293:97986.

[2] Kaya MG, Arslan F, Abaci A, van der Heijden G, Timurkaynak T, Cengel A. Myocardial blush grade: a predictor for major adverse cardiac events after primary PTCA with stent implantation for acute myocardial infarction. Acta Cardiol 2007; 62(October (5):445-51.

[3] Babaev A, Frederick PD, Pasta DJ, Every N, Sichrovsky T, Hochman JS; NRMI Investigators. Trends in management and outcomes of patients with acute myocardial infarction complicated by cardiogenic shock. JAMA 2005; 294:448-454.

[4] Weaver WD, Simes RJ, Betriu A, Grines $C L$, Zijlstra F, Garcia E, et al. Comparison of primary coronary angioplasty and intravenous thrombolytic therapy for acute myocardial infarction: a quantitative review. JAMA. 1997; 278:2093-2098.

[5] Nielsen PH, Maeng M, Busk M, Mortensen LS, Kristensen SD, Nielsen TT, et al. Primary angioplasty versus fibrinolysis in acute myocardial infarction: long-term follow-up in the Danish acute myocardial infarction 2 trial. Circulation. 2010; 121(13):1484-1491.

[6] Harigaya H, Motoyama S, Sarai M, Inoue K, Hara T, Okumura M, et al. Prediction of the noreflow phenomenon during percutaneous coronary intervention using coronary computed tomography angiography. Heart Vessels. 2011; 26(4):363-369.

[7] Brosh D, Assali AR, Mager A, Porter A, Hasdai D, Teplitsky I, et al. Effect of no reflow during primary percutaneous coronary intervention for acute myocardial infarction on six-month mortality. Am J Cardiol. 2007; 99:442-445.

[8] Jaffe R, Dick A, Strauss BH. Prevention and treatment of microvascular-related myocardial injury and coronary no-reflow following percutaneous coronary intervention: a systematic approach. J Am Coll Cardiol Interv. 2010; 3:695-704.

[9] Topsakal R, Kaya MG, Karakaya E, Günebakmaz O, Doğan A, Inanç MT, et al. Relationship between no-reflow phenomenon and serotonin levels in patients with acute STelevation myocardial infarction who underwent 


\section{Mohammad et al..}

primary percutaneous intervention. Anadolu Kardiyol Derg 2010; 10 June (3):253-9.

[10]Morishima I, Sone T, Okumura K, Tsuboi H, Kondo J, Mukawa H, et al. Angiographic noreflow phenomenon as a predictor of adverse long-term outcome in patients treated with percutaneous transluminal coronary angioplasty for first acute myocardial infarction. J Am Coll Cardiol 2000; 36:1202-9.

[11]Gibson CM, Schömig A. Coronary and Myocardial Angiography: Angiographic Assessment of Both Epicardial and Myocardial Perfusion. Circulation 2004; 109:3096-310.

[12]Cura FA, L'Allier PL, Kapadia SR, Houghtaling PL, Dipaola LM, Ellis SG, et al; GUSTO IIb and RAPPORT Investigators. Predictors and prognosis of suboptimal coronary blood flow after primary coronary angioplasty in patients with acute myocardial infarction. Am J Cardiol. 2001 Jul 15; 88(2):124-8.

[13]Kirma C, Izgi A, Dundar C, Tanalp AC, Oduncu V, Aung SM, et al. Clinical and procedural predictors of no-reflow phenomenon after primary percutaneous coronary interventions. Circ J 2008; 72: 716-721.

[14]Caixeta A, Lansky AJ, Mehran R, Brener SJ, Claessen B, Généreux $P$, et al. Predictors of suboptimal TIMI flow after primary angioplasty for acute myocardial infarction: results from the HORIZONS-AMI trial.EuroIntervention. 2013 Jun 22; 9(2):220-7.

[15]Nammas W, Pietilä M, Romppanen H, Sia J, DeBelder A, Karjalainen PP.. Outcome of poor initial TIMI flow in patients presenting with acute coronary syndrome. Scand Cardiovasc J. 2017 Oct; 51(5):248-254.

[16] Kammler J, Kypta A, Hofmann R, Kerschner K, Grund M, Sihorsch K, et al. TIMI 3 flow after primary angioplasty is an important predictor for
Zagazig University Medical Journals

outcome in patients with acute myocardial infarction. Clin Res Cardiol 2009; 98(3): 165-70.

[17]Chen ZW, Yu ZQ, Yang HB, Ying-Hua Chen, Ju-Ying Qian, Xian-Hong Shu, et al. Rapid predictors for the occurrence of reduced left ventricular ejection fraction between $\mathrm{LAD}$ and non-LAD related ST-elevation myocardial infarction. BMC Cardiovasc Disord. 2016; 16: 3.

[18]Karwowski J, Gierlotka M, Gąsior M, Poloński L, Ciszewski J, Bęćkowski M, et al. Relationship between infarct artery location, acute total coronary occlusion, and mortality in STEMI and NSTEMI patients. Pol Arch Intern Med. 2017 Jun 30; 127(6):401-411.

[19]De Luca G, Ernst N, Zijlstra F, van 't Hof AW, Hoorntje JC, Dambrink JH, et al. Preprocedural TIMI flow and mortality in patients with acute myocardial infarction treated by primary angioplasty. J Am Coll Cardiol. 2004 Apr 21; 43(8):1363-7.

[20]Ndrepepa G, Mehilli J, Schul, S, Iijima R, Keta $D$, Byrne RA, et al. Prognostic significance of epicardial blood flow before and after percutaneous coronary intervention in patients with acute coronary syndromes. J Am Coll Cardiol. 2008 Aug 12; 52(7):512-7.

[21]Rakowski T, Dudek D, Dziewierz A, Yи J, Witzenbichler B, Guagliumi G, et al. Impact of infarct-related artery patency before primary PCI on outcome in patients with ST-segment elevation myocardial infarction: the HORIZONS-AMI trial. EuroIntervention 2013;8:1307-1314

[22]Reeves RR, Patel M, Armstrong EJ, Sab S, Waldo $S W$, Yeo $K K$, et al. Angiographic characteristics of definite stent thrombosis: role of thrombus grade, collaterals, epicardial coronary flow, and myocardial perfusion. Catheter Cardiovasc Interv. 2015 Jan 1; 85(1):13-22.

How to cite this article: Mohammad IA, Mesbah TH, Tamer MM, Wael AK. Impact of Infarct Related Artery and Its Patency on The Outcomes of Patients Undergoing Primary Percutaneous Coronary

Intervention.ZUMJ 2019; 25 (2); 234-24.DOI: 10.21608/ZUMJ.2019.27409 